University of Nebraska - Lincoln

DigitalCommons@University of Nebraska - Lincoln

Faculty Papers and Publications in Animal

Science

Animal Science Department

January 1990

BREEDING VALUE PREDICTION WITH MATERNAL GENETIC GROUPS

L. Dale Van Vleck

University of Nebraska-Lincoln, dvan-vleck1@unl.edu

Follow this and additional works at: https://digitalcommons.unl.edu/animalscifacpub

Part of the Animal Sciences Commons

Van Vleck, L. Dale, "BREEDING VALUE PREDICTION WITH MATERNAL GENETIC GROUPS" (1990). Faculty Papers and Publications in Animal Science. 349.

https://digitalcommons.unl.edu/animalscifacpub/349

This Article is brought to you for free and open access by the Animal Science Department at DigitalCommons@University of Nebraska - Lincoln. It has been accepted for inclusion in Faculty Papers and Publications in Animal Science by an authorized administrator of DigitalCommons@University of Nebraska - Lincoln. 


\title{
BREEDING VALUE PREDICTION WITH MATERNAL GENETIC GROUPS1
}

\author{
L. D. Van Vleck ${ }^{2}$ \\ U.S. Department of Agriculture, Lincoln 68583-0908
}

\begin{abstract}
For models with only additive direct genetic effects, the rules of Westell combined with the Q-P transformation can be used to calculate the coefficients of mixed-model equations corresponding to the inverse elements of the numerator relationship matrix and group effects that are used to account for selection on ancestors that do not have records. Groups generally can be assigned on the basis of most recent ancestors without records. When maternal effects are in the model, most recent female ancestors without records contribute maternal effects to their progeny. If the vectors for additive direct and maternal effects do not include the same animals, numerator relationship matrices for direct and maternal effects and between direct and maternal effects are different. Even if they are the same, the Q-P transformation and Westell's rules do not lead to simplification for calculation of the coefficient matrix unless group assignment is the same for direct and maternal effects. This result can be achieved by including each female ancestor with offspring having records in both vectors and by assigning both of her parents to the same group she would have been assigned for a model including only direct effects. This strategy is equivalent to assigning group effects similarly for both direct and maternal effects and allows making use of the computational efficiency available from the Q-P transformation and Westell's rules, which are similar to Henderson's rules for calculating the inverse of the numerator relationship matrix.

(Key Words: Maternal Effects, Genetic Analysis, Genotypes, Transformation, Breeding Value.)
\end{abstract}

J. Anim. Sci. 1990. 68:3998-4013

\section{Introduction}

Effects of genetic groups can be included in models used for genetic evaluation to account for prior selection that resulted in base animals for which records are not available to the genetic evaluation (Thompson, 1979; Quaas and Pollak, 1981; Westell, 1984; Robinson, 1986; Quaas, 1988). If base animals are from one birth period and all are selected in the same way, then one genetic group is sufficient. A single genetic group is implied when genetic groups are not included in the model used for evaluation. Base animals, by necessity as well as logically, usually are defined as those most recent ancestors that do not have records or collateral (e.g., paternal halfsib) descendants. Nearly all, if not all, data sets for genetic evaluation include records associated with base animals from different time periods and selection paths. If selection has occurred, then ignoring differences in groups has two major consequences in prediction of breeding values. Essentially, the predictions involve regression to the average group effect rather than to the appropriate group effects. Rankings of animals with base ancestors from different time periods and selection paths can be affected. The other consequence arises when new data are added that include base animals from later time periods. Evaluations of older animals with no new

\footnotetext{
'Published as Paper No. 8981, Journal Ser., Nebraska Agric. Res. Div., Univ. of Nebraska, Lincoln.

2ARS, Roman L. Hruska U.S. Meat Anim. Res. Center, A218 Anim. Sci., Univ. of Nebraska, Lincoln 68583-0908.

Received July 5, 1989.

Accepted December 14, 1989.
} 
information (records or relatives) may change (i.e., float), because the implied assumption that the base for the evaluation has been set by an unchanging base population is not correct. Groups can be assigned arbitrarily but should logically account for different genetic means from different time periods or subpopulations. Westell (1984) and Robinson (1986) proposed assignment of groups by time period and selection path.

First a model with maternal effects but without genetic group effects will be developed, then in the Results section genetic group effects will be added for direct and maternal effects.

The usual mixed model is:

$y$ ㅁ $X \beta+Z u+e$

with

$$
\begin{gathered}
\mathrm{E}[\mathrm{y}]=\mathrm{X} \beta \text { and } \\
\mathrm{V}\left(\begin{array}{l}
\mathrm{y} \\
\mathrm{u} \\
\mathrm{e}
\end{array}\right)=\left(\begin{array}{ccc}
\mathrm{ZGZ^{ \prime } + \mathrm { R }} & \mathrm{ZG} & \mathrm{R} \\
\mathrm{GZ} & \mathrm{G} & 0 \\
0 & 0 & \mathrm{R}
\end{array}\right)
\end{gathered}
$$

For $\mathrm{R} \square \mathrm{I} \sigma_{\mathrm{e}}^{2}$ the corresponding mixed-model equations (MME) after multiplying both sides by $\sigma_{\mathrm{e}}^{2}$ are:

$$
\left(\begin{array}{ll}
X^{\prime} X & X^{\prime} Z \\
Z^{\prime} X & Z^{\prime} Z+G^{-1} \sigma_{\mathrm{e}}^{2}
\end{array}\right)\left(\begin{array}{l}
\hat{\beta} \\
\hat{u}
\end{array}\right)=\left(\begin{array}{l}
X^{\prime} y \\
Z^{\prime} y
\end{array}\right)
$$

This model is common for single-trait analyses. The MME can be solved by iteration but $\mathrm{G}$ must be inverted to set up the coefficient matrix. Henderson (1976) simplified that problem when $u$ is a vector of additive genetic values or if $u$ can be partitioned into a vector of additive genetic values, $a$, and a vector with a diagonal variance-covariance matrix that is uncorrelated with the vector of additive genetic values. For $\mathrm{A}$, the numerator relationship matrix, and $\sigma_{\mathrm{a}}^{2}$, the additive genetic variance, the part of $G$ corresponding to $a$ is $A \sigma_{a}^{2}$ and the corresponding part of $G^{-1}$ is $A^{-1}\left(1 / \sigma_{a}^{2}\right)$ for an animal model and $\mathrm{A}^{-1}\left(4 / \sigma_{a}^{2}\right)$ for a sire model. Henderson's (1976) rules for calculating $\mathrm{A}^{-1}$ and his demonstration of the use of an equivalent model to augment the mixed-model equations to include the base animals that are without records but that are needed to calculate $A^{-1}$ greatly changed genetic evaluations (Henderson, 1976, 1977). Henderson (1988) indicated that when other genetic effects (additive by additive, dominance, etc.) are included in the model a similar simplification has not been found.

Including maternal effects in an animal model would seem potentially to be even more complicated because the maternal effects come from the dam. For example, assume that additive direct, a, and additive maternal, $m$, effects are the only genetic effects in $u$, and other effects in $u$, such as nongenetic maternal effects, satisfy the uncorrelated and diagonal variance requirements. For algebraic convenience assume

$$
\mathrm{u}=\left(\begin{array}{l}
\mathrm{a} \\
\mathrm{m}
\end{array}\right)
$$

Then $\quad V(u)=G=\left(\begin{array}{ll}A \sigma_{\mathrm{a}}^{2} & \mathrm{~B} \sigma_{\mathrm{am}} \\ \mathrm{B}^{\prime} \sigma_{\mathrm{am}} & \mathrm{M} \sigma_{\mathrm{m}}^{2}\end{array}\right)$ where

$\left(\begin{array}{ll}A & B \\ B^{\prime} & M\end{array}\right)$ covariance between direct and maternal genetic effects in the same animal and $\sigma_{\mathrm{m}}^{2}$ is the variance of genetic maternal effects. Note that $B$ would normally correspond to numerator relationships between animals with records and their dams. 
A common way of setting up the model would be to include in a animals with records and to include in $\mathrm{m}$ females with progeny.

The problem is that there is no obvious simplification to obtain $\mathrm{G}^{-1}$, i.e., first calculate

$$
\mathrm{G}=\left(\begin{array}{ll}
\mathrm{A} \sigma_{\mathrm{a}}^{2} & \mathrm{~B} \sigma_{\mathrm{am}} \\
\mathrm{B}^{\prime} \sigma_{\mathrm{am}} & \mathrm{M} \sigma_{\mathrm{m}}^{2}
\end{array}\right)
$$

and then invert $G$. Henderson's (1976) rules for calculating $A^{-1}$ and $M$

' would require augmenting the vectors $a$ and $m$ to include base animals so that $a^{\prime}=\left(a_{1} a_{0}\right)^{\prime}$ and $m^{\prime}=\left(m_{1} m_{0}\right)^{\prime}$, where $a_{0}$ corresponds to the base animals for animals with records and $m_{0}$ corresponds to the base animals for mothers. Development of the rules of Westell (1984) (also see Westell et al., 1984, 1988; Quaas and Pollak, 1987; Quaas, 1988) for easy computation of coefficients of the MME for animals in $a_{1}$ and for genetic groups also requires $a_{0}$, or for the computations requires assignment of animals in $\mathrm{a}_{0}$ to groups. Those rules were derived by examining $\mathrm{G}^{-1}$ and what happens with absorption of equations for base animals into the other equations after Q-P transformation of the equations to jointly predict breeding values and group effects rather than to predict group effects and deviations from group effects (Quaas and Pollak, 1981).

In more general terms, then,



where the $A_{i j}$ are relationships among recorded and base animals for animals with records, the $M_{i j}$ are relationships among mothers with progeny with records and base animals of mothers, and the $B_{i j}$ are the relationships between animals in $\left(a_{1}^{\prime} a_{0}^{\prime}\right)^{\prime}$ and those in $\left(m_{l}^{\prime} m_{0}^{\prime}\right)^{\prime}$.

Unless the same animals are in a and $m$, there does not appear to be any obvious simplification to obtain $\mathrm{G}^{-1}$, or for the absorption of equations for base animals.

If the same animals are in a and $m$ (essentially more base animals are included in $\mathrm{a}_{0}$ to allow parents of mothers to be included and mothers with no records to be included in $a_{1}$ and to include in $m_{1}$ animals that are not parents) then

$$
G=\left(\begin{array}{ll}
\left(\begin{array}{ll}
A_{11} & A_{10} \\
A_{01} & A_{00}
\end{array}\right) \sigma_{a}^{2} & \left(\begin{array}{ll}
A_{11} & A_{10} \\
A_{01} & A_{00}
\end{array}\right) \sigma_{a m} \\
\left(\begin{array}{ll}
A_{11} & A_{10} \\
A_{01} & A_{00}
\end{array}\right) \sigma_{a m} & \left(\begin{array}{ll}
A_{11} & A_{10} \\
A_{01} & A_{00}
\end{array}\right) \sigma_{00}^{2}
\end{array}\right)=G_{0} *\left(\begin{array}{ll}
A_{11} & A_{10} \\
A_{01} & A_{00}
\end{array}\right)
$$

where $\mathrm{G}_{0}=\left(\begin{array}{ll}\sigma_{\mathrm{a}}^{2} & \sigma_{\mathrm{am}} \\ \sigma_{\mathrm{am}} & \sigma_{\mathrm{m}}^{2}\end{array}\right)$ and * is the right direct product operator.

Making the a and $m$ vectors larger in this way contributes substantially to simplifying computation of $\mathrm{G}^{-1}$ because by rules of direct products 


$$
\mathrm{G}^{-1}=\mathrm{G}_{0}^{-1} *\left(\begin{array}{ll}
\mathrm{A}_{11} & \mathrm{~A}_{10} \\
\mathrm{~A}_{01} & \mathrm{~A}_{00}
\end{array}\right)^{-1}
$$

where the inverse of this A can be computed according to Henderson's (1976) rules. This step also allows simplification when groups are included in the model after the Q-P transformation and absorption of base animals, those unrelated animals in $\mathrm{a}_{0}$ that are the same as those in $\mathrm{m}_{0}$. As will be shown later, dams without records, but that have at least one progeny with a record, are added to $a_{1}$. For a maternal effects model with genetic groups, both parents of such dams are then assigned to the genetic group that the dam, as a base animal, would have been assigned for models with only direct effects.

\section{Results}

\section{Mixed-Model Equations for Model with Direct and Maternal Genetic Effects}

The fractional contribution of genetic group effects to breeding values is $A_{10} Q_{0} g_{a}$ for additive direct genetic effects and $A_{10} Q_{0} g_{m}$ for maternal genetic effects with $Q_{0}$ a matrix that assigns base animals to groups (Thompson, 1979; Westell, 1984; Westell et al., 1984, 1988; Robinson, 1986; Quaas, 1988; Wiggans et al., 1988). Then the model for animals with records, $y$, is

$$
y=X \beta+Z a_{1}+Z A_{10} Q_{0} g_{a}+S m_{1}+S A_{10} Q_{0} g_{m}+e
$$

where $X$ associates fixed effects in $\beta$ with $y, Z$ associates additive genetic effects in $a_{1}$ with $y$, $\mathrm{ZA}_{10} \mathrm{Q}_{0}$ associates additive direct group effects in $\mathrm{g}_{\mathrm{a}}$ with $\mathrm{y}, \mathrm{S}$ associates maternal genetic effects in $\mathrm{m}_{1}$ with $\mathrm{y}, \mathrm{SA}_{10} \mathrm{Q}_{0}$ associates maternal group effects in $\mathrm{g}_{\mathrm{m}}$ with $\mathrm{y}$ and $\mathrm{e}$ is a vector of independent residuals. Note that $\mathrm{Z}$ will be an identity matrix if repeated records are not considered. Non-base animals without records can be included in a or $\mathrm{m}$ by including a corresponding zero row in $\mathrm{y}$, $\mathrm{X}, \mathrm{Z}$ and $\mathrm{S}$.

$$
E\left(\begin{array}{c}
y \\
a_{1} \\
m_{1} \\
\mathrm{e}
\end{array}\right)=\left(\begin{array}{c}
X \beta+Z A_{10} Q_{0} g_{a}+S A_{10} Q_{0} g_{m} \\
0 \\
0 \\
0
\end{array}\right)
$$

For the same animals in $a_{1}$ and $m_{1}$

$$
\mathrm{V}\left(\begin{array}{c}
\mathrm{a}_{1} \\
\mathrm{~m}_{1} \\
\mathrm{e}
\end{array}\right)=\left(\begin{array}{ccc}
\mathrm{A}_{11} \sigma_{\mathrm{a}}^{2} & \mathrm{~A}_{11} \sigma_{\mathrm{am}} & 0 \\
\mathrm{~A}_{11} \sigma_{\mathrm{am}} & \mathrm{A}_{11} \sigma_{\mathrm{m}}^{2} & 0 \\
0 & 0 & \mathrm{I} \sigma_{\mathrm{e}}^{2}
\end{array}\right)
$$

where $A_{11}$ is the numerator relationship matrix among animals in $a_{1}\left(\right.$ and $m_{1}$ ).

To augment the mixed-model equations, base animals with direct and maternal effects, $a_{0}$ and $\mathrm{m}_{0}$, will be included so that

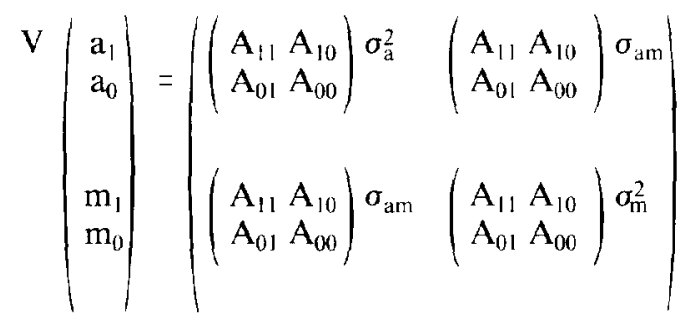




$$
\begin{aligned}
& =\mathrm{G}_{0} * \mathrm{~A} \text {, where } \mathrm{G}_{0}=\left(\begin{array}{c}
\sigma_{\mathrm{a}}^{2} \sigma_{\mathrm{am}} \\
\sigma_{\mathrm{am}} \sigma_{\mathrm{m}}^{2}
\end{array}\right) \\
& A=\left(\begin{array}{ll}
A_{11} & A_{10} \\
A_{01} & A_{00}
\end{array}\right)^{\text {and }}
\end{aligned}
$$

with $\mathrm{A}_{10}$ the part of the numerator relationship matrix for relationships between animals in $\mathrm{a}_{1}$ (or $\left.\mathrm{m}_{1}\right)$ and base animals in $\mathrm{a}_{0}\left(\right.$ or $\left.\mathrm{m}_{0}\right)$ and $\mathrm{A}_{00}$ the numerator relationship matrix among base animals (defined here to be the identity matrix).

A non-genetic maternal effect easily can be added that is uncorrelated with a or $\mathrm{m}$, but because this adds nothing to this development this nongenetic maternal effect will be included later.

$$
\text { Let }\left(\begin{array}{ll}
\alpha & \lambda \\
\lambda & \gamma
\end{array}\right)=\sigma_{\mathrm{e}}^{2}\left(\begin{array}{cc}
\sigma_{\mathrm{a}}^{2} & \sigma_{\mathrm{am}} \\
\sigma_{\mathrm{am}} & \sigma_{\mathrm{m}}^{2}
\end{array}\right)^{-1}
$$

Let $Q=A_{10} Q_{0}$ to save space in writing the equations. The coefficient matrix, $(C)$, for the mixedmodel equations augmented for base animals, i.e., with vectors, $\hat{a}_{0}$ and $\hat{m}_{0}$, (after all coefficients and right-hand sides are multiplied by $\sigma_{\mathrm{e}}^{2}$ ) is:

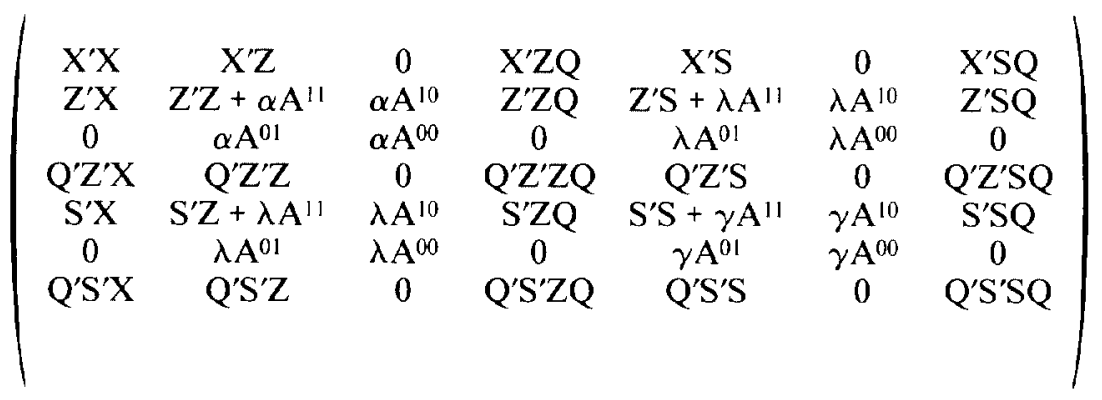

The vectors of solutions, s, and right-hand sides, $r$, are:

$$
\mathrm{s}=\left(\begin{array}{c}
\hat{\beta} \\
\hat{\mathrm{a}}_{1} \\
\hat{\mathrm{a}}_{0} \\
\hat{\mathrm{g}}_{\mathrm{a}} \\
\mathrm{m}_{\mathrm{1}} \\
\hat{\mathrm{m}}_{0} \\
\hat{\mathrm{g}}_{\mathrm{m}}
\end{array}\right) \quad \mathrm{r}=\left(\begin{array}{c}
\mathrm{X}^{\prime} \mathrm{y} \\
\mathrm{Z}^{\prime} \mathrm{y} \\
0 \\
\mathrm{Q}^{\prime} \mathrm{Z}^{\prime} \mathrm{y} \\
\mathrm{S}^{\prime} \mathrm{y} \\
0 \\
\mathrm{Q}^{\prime} \mathrm{S}^{\prime} \mathrm{y}
\end{array}\right)
$$

\section{The Q-P Transformation}

The Q-P transformation (Quaas and Pollak, 1981) for the equations Cs $\square \mathrm{r}$, modifies the solution vector by inserting the identity matrix, $\left(\mathrm{P}^{-1} \mathrm{P}\right)$, between $\mathrm{C}$ and $\mathrm{s}$ and then premultiplies both sides by $\mathrm{P}^{-\mathrm{T}}$ to retain symmetry:

$$
\mathbf{P}^{-\mathrm{T}} \mathrm{C}\left(\mathrm{P}^{-1} \mathbf{P}\right) \mathrm{s} \text { 口 } \mathbf{P}^{-\mathrm{T}} \mathbf{r} \text {. }
$$

An appropriate $P$ matrix is: 


$$
\left(\begin{array}{ccccccc}
\mathrm{I} & 0 & 0 & 0 & 0 & 0 & 0 \\
0 & \mathrm{I} & 0 & \mathrm{Q} & 0 & 0 & 0 \\
0 & 0 & \mathrm{I} & \mathrm{Q}_{0} & 0 & 0 & 0 \\
0 & 0 & 0 & \mathrm{I} & 0 & 0 & 0 \\
0 & 0 & 0 & 0 & \mathrm{I} & 0 & \mathrm{Q} \\
0 & 0 & 0 & 0 & 0 & \mathrm{I} & \mathrm{Q}_{0} \\
0 & 0 & 0 & 0 & 0 & 0 & \mathrm{I} \\
& & & & & &
\end{array}\right)
$$

The transpose of the inverse of $\mathrm{P}, \mathrm{P}^{-\mathrm{T}}$, is:

$$
\left(\begin{array}{ccccccc} 
& & & & & & \\
\mathrm{I} & 0 & 0 & 0 & 0 & 0 & 0 \\
0 & \mathrm{I} & 0 & 0 & 0 & 0 & 0 \\
0 & 0 & \mathrm{I} & 0 & 0 & 0 & 0 \\
0 & -\mathrm{Q}^{\prime} & -\mathrm{Q}^{\prime} & \mathrm{I} & 0 & 0 & 0 \\
0 & 0 & 0 & 0 & \mathrm{I} & 0 & 0 \\
0 & 0 & 0 & 0 & 0 & \mathrm{I} & 0 \\
0 & 0 & 0 & 0 & -\mathrm{Q}^{\prime} & -\mathrm{Q}^{\prime} & \mathrm{I}
\end{array}\right)
$$

The new solution vector, $s^{*}=P s$, and new right-hand side vector, $r^{*}{ }^{-P^{-T}} r$, are:

$$
\mathrm{s}^{*}=\left(\begin{array}{c}
\hat{\beta} \\
\hat{\mathrm{a}}_{1}+\mathrm{Qg}_{\mathrm{a}} \\
\hat{\mathrm{a}}_{0}+\mathrm{Q}_{0} \hat{\mathrm{g}}_{\mathrm{a}} \\
\hat{\mathrm{g}}_{\mathrm{a}} \\
\hat{\mathrm{m}}_{1}+\mathrm{Qg}_{\mathrm{m}} \\
\hat{\mathrm{m}}_{0}+\mathrm{Q}_{0} \hat{\mathrm{g}}_{\mathrm{m}} \\
\hat{\mathrm{g}}_{\mathrm{m}}
\end{array}\right) \quad \quad \text { and } \quad \mathrm{r}^{*}=\left(\begin{array}{c}
\mathrm{X}^{\prime} \mathrm{y} \\
\mathrm{Z}^{\prime} \mathrm{y} \\
0 \\
0 \\
\end{array}\right)
$$

The transformed coefficient matrix, $\mathrm{C}^{*}=\mathrm{P}^{-\mathrm{T}} \mathrm{CP}^{-1}$, is:

$$
\left(\begin{array}{ccccccc} 
& & \multicolumn{5}{c}{} \\
\mathrm{X}^{\prime} \mathrm{X} & \mathrm{X}^{\prime} \mathrm{Z} & 0 & 0 & \mathrm{X}^{\prime} \mathrm{S} & 0 & 0 \\
\mathrm{Z}^{\prime} \mathrm{X} & \mathrm{Z}^{\prime} \mathrm{Z}+\alpha \mathrm{A}^{11} & \alpha \mathrm{A}^{10} & 0 & \mathrm{Z}^{\prime} \mathrm{S}+\lambda \mathrm{A}^{11} & \lambda \mathrm{A}^{10} & 0 \\
0 & \alpha \mathrm{A}^{01} & \alpha \mathrm{A}^{00} & -\alpha \mathrm{Q}_{0} & \lambda \mathrm{A}^{01} & \lambda \mathrm{A}^{00} & -\lambda \mathrm{Q}_{0} \\
0 & 0 & -\alpha \mathrm{Q}^{\prime} & \alpha \mathrm{Q}_{0}^{\prime} \mathrm{Q}_{0} & 0 & -\lambda \mathrm{Q}^{\prime} & \lambda \mathrm{Q}_{0}^{\prime} \mathrm{Q}_{0} \\
\mathrm{~S}^{\prime} \mathrm{X} & \mathrm{S}^{\prime} \mathrm{Z}+\lambda \mathrm{A}^{11} & \lambda \mathrm{A}^{10} & 0 & \mathrm{~S}^{\prime} \mathrm{S}+\gamma \mathrm{A}^{11} & \gamma \mathrm{A}^{10} & 0 \\
0 & \lambda \mathrm{A}^{01} & \lambda \mathrm{A}^{00} & -\lambda \mathrm{Q}_{0} & \gamma \mathrm{A}^{01} & \gamma \mathrm{A}^{00} & -\gamma \mathrm{Q}_{0} \\
0 & 0 & -\lambda \mathrm{Q}^{\prime} & -\lambda \mathrm{Q}_{0}^{\prime} \mathrm{Q}_{0} & 0 & -\gamma \mathrm{Q}_{0}^{\prime} & \gamma \mathrm{Q}_{0}^{\prime} \mathrm{Q}_{0} \\
& & & & & &
\end{array}\right)
$$


Absorption of Equations for Base Animals

To demonstrate absorption of equations for direct and maternal effects of base animals, the rows and columns in $\mathrm{C}^{*}$ can be reordered as:

$$
\left(\begin{array}{ccccccc}
\alpha \mathrm{A}^{00} & \lambda \mathrm{A}^{00} & 0 & \alpha \mathrm{A}^{01} & \lambda \mathrm{A}^{01} & -\alpha \mathrm{Q}_{0} & -\lambda \mathrm{Q}_{0} \\
\lambda \mathrm{A}^{00} & \gamma \mathrm{A}^{00} & 0 & \lambda \mathrm{A}^{01} & \gamma \mathrm{A}^{01} & -\lambda \mathrm{Q}_{0} & -\gamma \mathrm{Q}_{0} \\
0 & 0 & \mathrm{X}^{\prime} \mathrm{X} & \mathrm{X}^{\prime} \mathrm{Z} & \mathrm{X}^{\prime} \mathrm{S} & 0 & 0 \\
\alpha \mathrm{A}^{10} & \lambda \mathrm{A}^{10} & \mathrm{Z}^{\prime} \mathrm{X} & \mathrm{Z}^{\prime} \mathrm{Z}^{+}+\alpha \mathrm{A}^{11} & \mathrm{Z}^{\prime} \mathrm{S}^{+}+\lambda \mathrm{A}^{11} & 0 & 0 \\
\lambda \mathrm{A}^{10} & \gamma \mathrm{A}^{10} & \mathrm{~S}^{\prime} \mathrm{X} & \mathrm{S}^{\prime} \mathrm{Z}+\lambda \mathrm{A}^{11} & \mathrm{~S}^{\prime} \mathrm{S}+\gamma \mathrm{A}^{11} & 0 & 0 \\
-\alpha \mathrm{Q}^{\prime} & -\lambda \mathrm{Q}^{\prime} & 0 & 0 & 0 & \alpha \mathrm{Q}_{0}^{\prime} \mathrm{Q}_{0} & \lambda \mathrm{Q}_{0}^{\prime} \mathrm{Q}_{0} \\
-\lambda \mathrm{Q}^{\prime} & -\gamma \mathrm{Q}^{\prime} & 0 & 0 & 0 & \lambda \mathrm{Q}_{0}^{\prime} \mathrm{Q}_{0} & \gamma \mathrm{Q}_{0}^{\prime} \mathrm{Q}_{0}
\end{array}\right)\left(\begin{array}{c}
\hat{\mathrm{a}}_{0}+\mathrm{Q}_{0} \hat{\mathrm{g}}_{\mathrm{a}} \\
\hat{\mathrm{m}}_{0}+\mathrm{Q}_{0} \hat{\mathrm{g}}_{\mathrm{m}} \\
\hat{\beta} \\
\hat{\mathrm{a}}_{1}+\mathrm{Q}_{\mathrm{g}} \\
\hat{\mathrm{m}}_{1}+\mathrm{Q}_{\mathrm{g}} \\
\hat{\mathrm{g}}_{\mathrm{m}} \\
\hat{\mathrm{g}}_{\mathrm{m}}
\end{array}\right)=\left(\begin{array}{c}
0 \\
0 \\
\mathrm{X}^{\prime} \mathrm{y} \\
\mathrm{Z}^{\prime} \mathrm{y} \\
\mathrm{S}^{\prime} \mathrm{y} \\
0 \\
0
\end{array}\right)
$$

Absorption of $\hat{\mathrm{a}}_{0}+\mathrm{Q}_{0} \hat{\mathrm{g}}_{\mathrm{a}}$ and $\hat{\mathrm{m}}_{0}+\mathrm{Q}_{0} \hat{\mathrm{g}}_{\mathrm{m}}$ will not change the rows and columns associated with $\beta$ and also will not change any of the right-hand sides.

$$
\text { Let } G_{1}^{-1}=\left(\begin{array}{ll}
\alpha & \lambda \\
\lambda & \gamma
\end{array}\right)
$$

The coefficients for the equations, other than for $\beta$, can be written in direct product notation as:

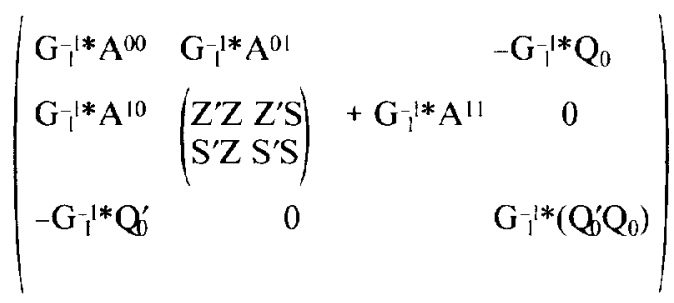

The absorption results in:

$$
\left(\begin{array}{cccc}
\left(\begin{array}{c}
Z^{\prime} Z Z^{\prime} S \\
S^{\prime} Z S^{\prime} S
\end{array}\right) & + & \mathrm{G}_{1}^{-1 *} \mathrm{~W}_{11} & \mathrm{G}_{1}^{-1 *} \mathrm{~W}_{12} \\
& & & \\
& \mathrm{G}_{1}^{-1 *} \mathrm{~W}_{12}^{\prime} & & \mathrm{G}_{1}^{-1 *} \mathrm{~W}_{22}
\end{array}\right)
$$

where

$$
\begin{aligned}
& W_{11}=A^{11}-A^{10}\left(A^{00}\right)^{-1} A^{01}=A_{11}^{-11} \\
& W_{12}=A^{10}\left(A^{00}\right)^{-1} Q_{0} \quad=-A_{11}^{1} A_{10} Q_{0} \\
& W_{22}=Q_{0}^{\prime}\left[I-\left(A^{00}\right)^{-1}\right] Q_{0} \quad \square Q_{0}^{\prime} A_{01} A_{11}^{-1} A_{10} Q_{0}
\end{aligned}
$$

The terms in $\mathrm{W}_{\mathrm{ij}}$ can be calculated according to rules of Westell (see, e.g., Westell, 1984; Westell et al., 1984, 1988; Quaas, 1988; Wiggans et al., 1988), which, for completeness, are included here. Let $\mathrm{i}$ identify the animal,

$s$ identify the sire of animal $i$ if included in $a_{1}$ or the group of the sire if he is included in $a_{0}$. $d$ identify the dam of animal $i$ if included in $a_{1}$ or the group of the dam if she is included in $a_{0}$. Then for each animal in $\mathrm{a}_{1}$, contributions to elements of $\mathrm{W}$ will be as follows: 
$\mathrm{D}$ to $(\mathrm{i}, \mathrm{i})$

$-\mathrm{D} / 2$ to $(\mathrm{i}, \mathrm{s}),(\mathrm{i}, \mathrm{d}),(\mathrm{s}, \mathrm{i})$ and $(\mathrm{d}, \mathrm{i})$

$\mathrm{D} / 4$ to $(\mathrm{s}, \mathrm{s}),(\mathrm{s}, \mathrm{d}),(\mathrm{d}, \mathrm{s})$ and $(\mathrm{d}, \mathrm{d})$,

where: $D=2$ if both parents are in $a_{1}$,

$D=4 / 3$ if one parent is in $a_{1}$, and one parent is in $a_{0}$,

$\mathrm{D}=1$ if both parents are in $\mathrm{a}_{0}$.

If parents are related, then $\mathrm{D}=2$ is an approximation. The correct value can be obtained as described by Quaas (1976).

The resulting MME are

$$
\left(\begin{array}{ccccc} 
& & & & \\
\mathrm{X}^{\prime} \mathrm{X} & \mathrm{X}^{\prime} \mathrm{Z} & \mathrm{X} & 0 & 0 \\
\mathrm{Z}^{\prime} \mathrm{X} & \mathrm{Z}^{\prime} \mathrm{Z}+\alpha \mathrm{W}_{11} & \mathrm{Z}^{\prime} \mathrm{S}+\lambda \mathrm{W}_{11} & \alpha \mathrm{W}_{12} & \lambda \mathrm{W}_{12} \\
\mathrm{~S}^{\prime} \mathrm{X} & \mathrm{S}^{\prime} \mathrm{X}+\lambda \mathrm{W}_{11} & \mathrm{~S}^{\prime} \mathrm{S}+\gamma \mathrm{W}_{11} & \lambda \mathrm{W}_{12} & \gamma \mathrm{W}_{12} \\
0 & \alpha \mathrm{W}_{12}^{\prime} & \lambda \mathrm{W}_{12}^{\prime} & \alpha \mathrm{W}_{22} & \lambda \mathrm{W}_{22} \\
0 & \lambda \mathrm{W}_{12}^{\prime} & \gamma \mathrm{W}_{12}^{\prime} & \lambda \mathrm{W}_{22} & \gamma \mathrm{W}_{22}
\end{array}\right)\left(\begin{array}{c} 
\\
\hat{\beta} \\
\hat{\mathrm{a}}_{1}+\mathrm{Qg} \hat{\mathrm{g}}_{\mathrm{a}} \\
\hat{\mathrm{m}}_{1}+\mathrm{Q}_{\mathrm{m}} \\
\hat{\mathrm{g}}_{\mathrm{a}} \\
\hat{\mathrm{g}}_{\mathrm{m}}
\end{array}\right)=\left(\begin{array}{c} 
\\
\mathrm{X}^{\prime} \mathrm{y} \\
\mathrm{Z}^{\prime} \mathrm{y} \\
\mathrm{S}^{\prime} \mathrm{y} \\
0 \\
0
\end{array}\right)
$$

If fixed effects in $\beta$ are absorbed, as often is the case, then $Z^{\prime} Z, Z^{\prime} S, S^{\prime} S$ are replaced by $Z^{\prime} M Z$, $\mathrm{Z}^{\prime} \mathrm{MS}, \mathrm{S}^{\prime} \mathrm{MS}$, and $\mathrm{Z}^{\prime} \mathrm{y}, \mathrm{S}^{\prime} \mathrm{y}$ are replaced by $\mathrm{Z}^{\prime} \mathrm{My}, \mathrm{S}^{\prime} \mathrm{My}$ where $\mathrm{M}=\mathrm{I}-\mathrm{X}\left(\mathrm{X}^{\prime} \mathrm{X}\right)^{-} \mathrm{X}^{\prime}$.

If iteration is done on records (Schaeffer and Kennedy, 1986a, b), then the form shown above is nearly as simple as with only direct effects because in each equation any coefficient due to $\mathrm{W}$ is associated with a comparable direct and maternal effect with the appropriate constant $(\alpha, \lambda)$ or $(\gamma, \lambda)$, depending on whether the equation is for direct or maternal breeding value.

\section{Including a Nongenetic Maternal Effect}

A more realistic model would have included a vector of nongenetic maternal effects, $p$, if some dams have more than one progeny with records. If $\mathrm{p}$, with variance, $I \sigma_{\mathrm{p}}^{2}$, is uncorrelated with a, $m$ or $e$, then the $p$ equations pass through the Q-P transformation and absorption of the $\hat{a}_{0}$ and $\hat{\mathrm{m}}_{0}$ equations in the same way as the $\beta$ equations.

For $\delta \square \sigma_{\mathrm{e}}^{2} / \sigma_{\mathrm{p}}^{2}$ the comparable equations with $\mathrm{p}$ included are:

$$
\left(\begin{array}{cccccc}
\mathrm{X}^{\prime} \mathrm{X} & \mathrm{X}^{\prime} \mathrm{Z} & \mathrm{X}^{\prime} \mathrm{S} & \mathrm{X}^{\prime} \mathrm{S} & 0 & 0 \\
\mathrm{Z}^{\prime} \mathrm{X} & \mathrm{Z}^{\prime} \mathrm{Z}+\alpha \mathrm{W}_{11} & \mathrm{Z}^{\prime} \mathrm{S}+\lambda \mathrm{W}_{11} & \mathrm{Z}^{\prime} \mathrm{S} & \alpha \mathrm{W}_{12} & \lambda \mathrm{W}_{12} \\
\mathrm{~S}^{\prime} \mathrm{X} & \mathrm{S}^{\prime} \mathrm{Z}+\lambda \mathrm{W}_{11} & \mathrm{~S}^{\prime} \mathrm{S}+\gamma \mathrm{W}_{11} & \mathrm{~S}^{\prime} \mathrm{S} & \lambda \mathrm{W}_{12} & \gamma \mathrm{W}_{12} \\
\mathrm{~S}^{\prime} \mathrm{X} & \mathrm{SZ}^{\prime} \mathrm{Z} & \mathrm{S}^{\prime} \mathrm{S} & \mathrm{S}^{\prime} \mathrm{S}+\mathrm{I} \delta & 0 & 0 \\
0 & \alpha \mathrm{W}_{12}^{\prime} & \lambda \mathrm{W}_{12}^{\prime} & 0 & \alpha \mathrm{W}_{22} & \lambda \mathrm{W}_{22} \\
0 & \lambda \mathrm{W}_{12}^{\prime} & \gamma \mathrm{W}_{12}^{\prime} & 0 & \lambda \mathrm{W}_{22} & \gamma \mathrm{W}_{22}
\end{array}\right)\left(\begin{array}{c}
\hat{\beta} \\
\hat{\mathrm{a}}_{1}+\mathrm{Qg}_{\mathrm{a}} \\
\hat{\mathrm{m}}_{1}+\mathrm{Q} \hat{\mathrm{g}}_{\mathrm{m}} \\
\hat{\mathrm{p}} \\
\hat{\mathrm{g}}_{\mathrm{a}} \\
\hat{\mathrm{g}}_{\mathrm{m}}
\end{array}\right)=\left(\begin{array}{c}
\mathrm{X}^{\prime} \mathrm{y} \\
\mathrm{Z}^{\prime} \mathrm{y} \\
\mathrm{S}^{\prime} \mathrm{y} \\
\mathrm{S}^{\prime} \mathrm{y} \\
0 \\
0
\end{array}\right)
$$

\section{Calculation of $W$}

The equations can be reordered to put direct breeding value and direct group effects together in a form that may be used for computing. The resulting $M M E$ (with the nongenetic maternal effects ignored) are: 


$$
\left(\begin{array}{ccccc} 
& & & & \\
\mathrm{X}^{\prime} \mathrm{X} & \mathrm{X}^{\prime} \mathrm{Z} & 0 & \mathrm{X}^{\prime} \mathrm{S} & 0 \\
\mathrm{Z}^{\prime} \mathrm{X} & \mathrm{Z}^{\prime} \mathrm{Z}^{+}+\mathrm{W}_{11} & \alpha \mathrm{W}_{12} & \mathrm{Z}^{\prime} \mathrm{S}+\lambda \mathrm{W}_{11} & \lambda \mathrm{W}_{12} \\
0 & \alpha \mathrm{W}_{12}^{\prime} & \alpha \mathrm{W}_{22} & \lambda \mathrm{W}_{12}^{\prime} & \lambda \mathrm{W}_{22} \\
\mathrm{~S}^{\prime} \mathrm{X} & \mathrm{S}^{\prime} \mathrm{Z}+\lambda \mathrm{W}_{11} & \lambda \mathrm{W}_{12} & \mathrm{~S}^{\prime} \mathrm{S}+\gamma \mathrm{W}_{11} & \gamma \mathrm{W}_{12} \\
0 & \lambda \mathrm{W}_{12}^{\prime} & \lambda \mathrm{W}_{22} & \lambda \mathrm{W}_{12}^{\prime} & \gamma \mathrm{W}_{22}
\end{array}\right)\left(\begin{array}{c}
\hat{\beta} \\
\hat{\mathrm{a}}_{1}+\mathrm{Qg}_{\mathrm{a}} \\
\hat{\mathrm{g}}_{\mathrm{a}} \\
\hat{\mathrm{m}}_{1}+\mathrm{Q} \hat{\mathrm{g}}_{\mathrm{m}} \\
\hat{\mathrm{g}}_{\mathrm{m}}
\end{array}\right)=\left(\begin{array}{c}
\mathrm{X}^{\prime} \mathrm{y} \\
\mathrm{Z}^{\prime} \mathrm{y} \\
0 \\
\mathrm{~S}^{\prime} \mathrm{y} \\
0
\end{array}\right)
$$

In this form all the parts of $\mathrm{W}$ with the same multiplier $(\alpha, \lambda$ or $\gamma)$ are blocked together. The direct breeding value and direct group effects computationally are a subvector of solutions. For example, either in computing for real data or for examples, $\mathrm{Z}$ and $\mathrm{S}$ can be expanded to include null columns corresponding to the number of groups, i.e., $Z_{+} \square(Z 0)$.

Then the equations can be written as:

$$
\left(\begin{array}{ccc} 
& & \\
\mathrm{X}^{\prime} \mathrm{X} & \mathrm{X}^{\prime} \mathrm{Z}_{+} & \mathrm{X}^{\prime} \mathrm{S}_{+} \\
\mathrm{Z}_{+}^{\prime} \mathrm{X} & \mathrm{Z}_{+}^{\prime} \mathrm{Z}_{+}^{+}+\alpha \mathrm{W} & \mathrm{Z}_{+}^{\prime} \mathrm{S}_{+}+\lambda \mathrm{W} \\
\mathrm{S}_{+}^{\prime} \mathrm{X} & \mathrm{S}_{+}^{\prime} \mathrm{Z}_{+}+\lambda \mathrm{W} & \mathrm{S}_{+}^{\prime} \mathrm{S}_{+}+\gamma \mathrm{W}
\end{array}\right)\left(\begin{array}{c}
\hat{\beta} \\
\hat{\mathrm{a}}_{*} \\
\hat{\mathrm{m}}_{*}
\end{array}\right) \square\left(\begin{array}{c}
\mathrm{X}^{\prime} \mathrm{y} \\
\mathrm{Z}_{+}^{\prime} \mathrm{y} \\
\mathrm{S}^{\prime} \mathrm{y}
\end{array}\right)
$$

where $\hat{a}_{*} \mathbf{\square}\left(\begin{array}{c}\hat{\mathrm{a}}_{1}+\mathrm{Q} \hat{\mathrm{g}}_{\mathrm{a}} \\ \hat{\mathrm{g}}_{\mathrm{a}}\end{array}\right), \quad \hat{\mathrm{m}}_{*} \quad=\left(\begin{array}{c}\hat{\mathrm{m}}_{1}+\mathrm{Q} \hat{\mathrm{g}}_{\mathrm{m}} \\ \hat{\mathrm{g}}_{\mathrm{m}}\end{array}\right)$ and $\mathrm{W}=\left(\begin{array}{cc}\mathrm{W}_{11} & \mathrm{~W}_{12} \\ \mathrm{~W}_{12}^{\prime} & \mathrm{W}_{22}\end{array}\right)$

\section{Assigning Groups for Maternal Effects}

The final complication is how to assign groups with maternal effects included in the model. The usual rule is to trace pedigrees to animals without records (or other collateral descendants) and to assign those final (phantom) animals to appropriate groups. This rule would seem to be compromised with maternal effects. A "final" female may not have a record but would have maternal effects expressed in each of her progeny with a record.

Figure 1 shows a pedigree with groups assigned, based on direct effects. Female animals $\mathrm{B}, \mathrm{C}_{2}$, $\mathrm{C}_{3}$ and $\mathrm{C}_{4}$ and male, $\mathrm{C}_{1}$, have records. $\mathrm{S}$ (a male) is to be included in $\mathrm{a}_{1}$, has no records but has two collateral descendants. The animals labeled $P_{j},(j=1, \ldots, 7)$, are phantom (proxy) parents in

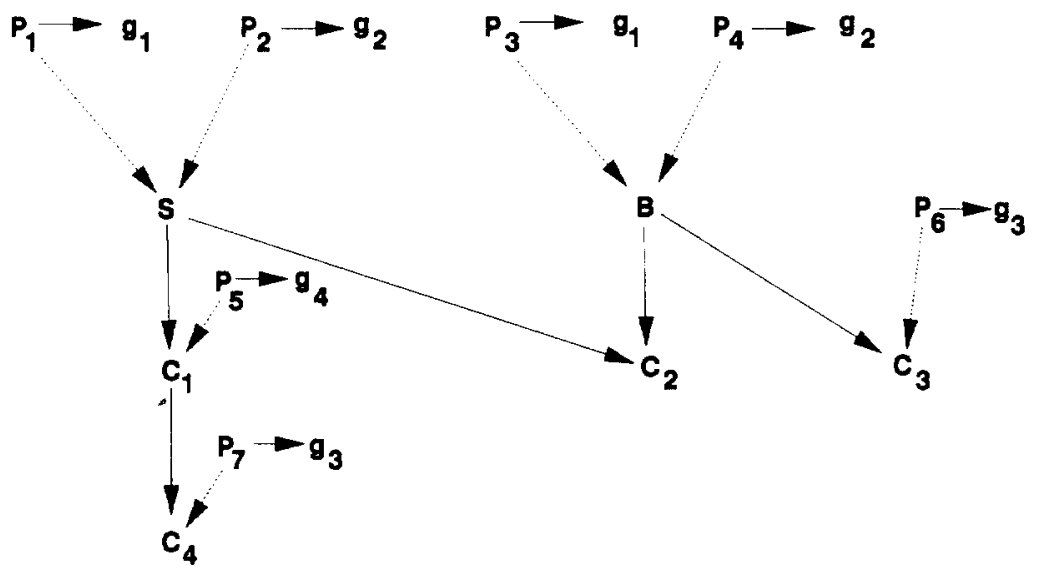

Figure 1. Example pedigree: females, $\left(B, C_{2}, C_{3}, C_{4}\right)$, and male $C_{1}$ have records. Male $S$ has two collateral descendants with records. Phantom (proxy) parents without records $\left(\mathrm{P}_{1}, \ldots, \mathrm{P}_{7}\right)$, are assigned to selected genetic base groups, $\left(g_{1}, \ldots, g_{4}\right)$ with $P_{4}$, the dam of $B$; $P_{5}$, the dam of $C_{1}$; and $P_{7}$, the dam of $C_{4}$. 
Westell's terminology and are base animals heading only one line of descent. Except for $\mathrm{P}_{6}$ and $\mathbf{P}_{7}$, they have been arbitrarily assigned to groups by time and path of selection (Robinson, 1986; Thompson, 1979; Westell, 1984; Quaas, 1988). Phantoms $P_{2}, P_{4}, P_{5}$, and $P_{7}$ are females. Phantom females $\mathrm{P}_{4}, \mathrm{P}_{5}$, and $\mathrm{P}_{7}$ contribute maternal effects to animals $\mathrm{B}, \mathrm{C}_{1}$, and $\mathrm{C}_{4}$ that have records.

\section{Genetic Model for Direct Effects}

Model equations for breeding values, BV, of animals in Figure 1 with records are:

$$
\begin{aligned}
& \mathrm{BV}_{\mathrm{B}} \square \mathrm{a}_{\mathrm{B}}+.5 \mathrm{~g}_{\mathrm{a}}+.5 \mathrm{ga}_{\mathrm{a}} \\
& \mathrm{BV}_{\mathrm{Cl}}=\mathrm{a}_{\mathrm{Cl}}+.25 \mathrm{~g}_{\mathrm{a}}+.25 \mathrm{~g}_{\mathrm{a} 2}+.5 \mathrm{~g}_{\mathrm{a} 4} \\
& \mathrm{BV}_{\mathrm{C} 2} \square \mathrm{a}_{\mathrm{C} 2}+.25 \mathrm{~g}_{\mathrm{a}}+.25 \mathrm{~g}_{\mathrm{a} 2}+.25 \mathrm{~g}_{\mathrm{a}}+.25 \mathrm{~g}_{\mathrm{a} 2} \\
& \mathrm{BV}_{\mathrm{C} 3} \text { 口 } \mathrm{a}_{\mathrm{C} 3}+.25 \mathrm{~g}_{\mathrm{al}}+.25 \mathrm{~g}_{\mathrm{a} 2}+.5 \mathrm{~g}_{\mathrm{a} 3} \\
& \mathrm{BV}_{\mathrm{C} 4} \text { 口 } \mathrm{a}_{\mathrm{C} 4}+.125 \mathrm{~g}_{\mathrm{a}}+.125 \mathrm{~g}_{\mathrm{a} 2}+.5 \mathrm{~g}_{\mathrm{a} 3}+.25 \mathrm{~g}_{\mathrm{a} 4}
\end{aligned}
$$

On this basis for the five animals with records,

$$
\operatorname{ZQg}_{\mathrm{a}}=\left(\begin{array}{llll}
.5 & .5 & 0 & 0 \\
.25 & .25 & 0 & .5 \\
.50 & .50 & 0 & 0 \\
.25 & .25 & .5 & 0 \\
.125 & .125 & .5 & .25
\end{array}\right) \quad\left(\begin{array}{l}
\mathrm{g}_{\mathrm{al}} \\
\mathrm{g}_{\mathrm{a} 2} \\
\mathrm{~g}_{\mathrm{a} 3} \\
\mathrm{~g}_{\mathrm{a} 4}
\end{array}\right)
$$

\section{Model for Genetic Maternal Effects}

The models for parts of the records due to maternal, MAT, effects (genetic only, no nongenetic in the example) are:

$$
\begin{aligned}
& \operatorname{MAT}_{\mathrm{B}}=\mathrm{m}_{\mathrm{P} 4}+\mathrm{g}_{\mathrm{m} 2} \\
& \operatorname{MAT}_{\mathrm{C} 1}=\mathrm{m}_{\mathrm{P5}}+\mathrm{g}_{\mathrm{m} 4} \\
& \mathrm{MAT}_{\mathrm{C} 2}=\mathrm{m}_{\mathrm{B}}+.5 \mathrm{~g}_{\mathrm{m} 1}+.5 \mathrm{~g}_{\mathrm{m} 2} \\
& \operatorname{MAT}_{\mathrm{C} 3}=\mathrm{m}_{\mathrm{B}}+.5 \mathrm{~g}_{\mathrm{ml}}+.5 \mathrm{~g}_{\mathrm{m} 2} \\
& \operatorname{MAT}_{\mathrm{C} 4}=\mathrm{m}_{\mathrm{P} 7}+\mathrm{g}_{\mathrm{m} 3}
\end{aligned}
$$

The base animals for a maternal effect trace only from the mother that expresses the effect in the records of her progeny. The effect on setting up the Q-P transformed and base animal absorbed MME is that animals such as $P_{4}, P_{5}$ and $P_{7}$ need to be included in $a_{1}$ and $m_{1}$. The rows of $\mathrm{Z}$ for $\mathrm{P}_{4}, \mathrm{P}_{5}, \mathrm{P}_{7}$ (and $\mathrm{S}$ ) will be null.

The $Q$ that worked for direct effects certainly does not work for maternal effects (i.e., if $g_{m}$ is substituted for $g_{a}$ ).

With animals in order $\mathrm{P}_{4}, \mathrm{P}_{5}, \mathrm{P}_{7}, \mathrm{~S}, \mathrm{~B}, \mathrm{C}_{1}, \mathrm{C}_{2}, \mathrm{C}_{3}, \mathrm{C}_{4}$

$$
\text { let } Z=\left(\begin{array}{lllllllll}
0 & 0 & 0 & 0 & 0 & 0 & 0 & 0 & 0 \\
0 & 0 & 0 & 0 & 0 & 0 & 0 & 0 & 0 \\
0 & 0 & 0 & 0 & 0 & 0 & 0 & 0 & 0 \\
0 & 0 & 0 & 0 & 0 & 0 & 0 & 0 & 0 \\
0 & 0 & 0 & 0 & 1 & 0 & 0 & 0 & 0 \\
0 & 0 & 0 & 0 & 0 & 1 & 0 & 0 & 0 \\
0 & 0 & 0 & 0 & 0 & 0 & 1 & 0 & 0 \\
0 & 0 & 0 & 0 & 0 & 0 & 0 & 1 & 0 \\
0 & 0 & 0 & 0 & 0 & 0 & 0 & 0 & 1
\end{array}\right), \quad S=\left(\begin{array}{ccccccccc}
0 & 0 & 0 & 0 & 0 & 0 & 0 & 0 & 0 \\
0 & 0 & 0 & 0 & 0 & 0 & 0 & 0 & 0 \\
0 & 0 & 0 & 0 & 0 & 0 & 0 & 0 & 0 \\
0 & 0 & 0 & 0 & 0 & 0 & 0 & 0 & 0 \\
1 & 0 & 0 & 0 & 0 & 0 & 0 & 0 & 0 \\
0 & 1 & 0 & 0 & 0 & 0 & 0 & 0 & 0 \\
0 & 0 & 0 & 0 & 1 & 0 & 0 & 0 & 0 \\
0 & 0 & 0 & 0 & 1 & 0 & 0 & 0 & 0 \\
0 & 0 & 1 & 0 & 0 & 0 & 0 & 0 & 0
\end{array}\right) \text {, and }
$$




$$
Q=\left(\begin{array}{cccc}
0 & 1 & 0 & 0 \\
0 & 0 & 0 & 1 \\
0 & 0 & 1 & 0 \\
1 / 2 & 1 / 2 & 0 & 0 \\
1 / 2 & 1 / 2 & 0 & 0 \\
1 / 4 & 1 / 4 & 0 & 1 / 2 \\
1 / 2 & 1 / 2 & 0 & 0 \\
1 / 4 & 1 / 4 & 1 / 2 & 0 \\
1 / 8 & 1 / 8 & 1 / 2 & 1 / 4
\end{array}\right)
$$

Note that $\mathrm{Za}_{1}+\mathrm{ZQg}_{\mathrm{a}}$ for $\mathrm{Z}_{9 \times 9}$ diagonal, with first four diagonals equal to zero and last five equal to 1 , is the same as the model equations for breeding values, with animals $\mathbf{P}_{4}, \mathbf{P}_{5}, \mathbf{P}_{7}$ and $S$ having null models, i.e.,

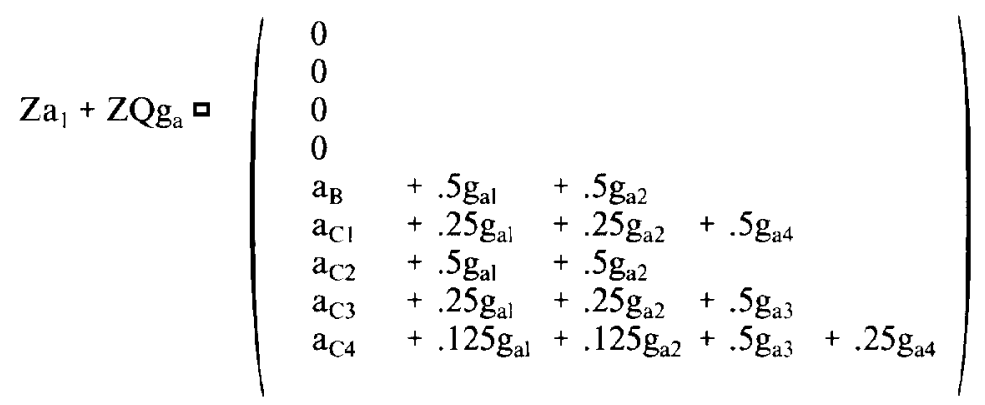

Also note that $\mathrm{Sm}_{1}+\mathrm{SQg}_{\mathrm{m}}$ is the same as the models for the parts of the records due to maternal effects with null records for animals $\mathrm{P}_{4}, \mathrm{P}_{5}, \mathrm{P}_{7}$, and $\mathrm{S}$ having null models, i.e.,

$$
\mathrm{Sm}_{1}+\mathrm{SQg}_{\mathrm{m}}=\left(\begin{array}{l}
0 \\
0 \\
0 \\
0 \\
\mathrm{~m}_{\mathrm{P} 4}+\mathrm{g}_{\mathrm{m} 2} \\
\mathrm{~m}_{\mathrm{P} 5}+\mathrm{g}_{\mathrm{m} 4}+.5 \mathrm{~g}_{\mathrm{m} 2} \\
\mathrm{~m}_{\mathrm{B}}+.5 \mathrm{~g}_{\mathrm{m} 1}+.5 \mathrm{~g}_{\mathrm{m} 2} \\
\mathrm{~m}_{\mathrm{B}}+.5 \mathrm{~g}_{\mathrm{m} 1} \\
\mathrm{~m}_{\mathrm{P} 7}+\mathrm{g}_{\mathrm{m} 3}
\end{array}\right)
$$

Thus, the models seem to be equivalent (Henderson, 1985). The computation of $\mathrm{W}$, however, involves $\mathrm{Q}_{0}$ rather than $\mathrm{Q}$.

Base animals in $\mathrm{a}_{0}$ and $\mathrm{m}_{0}$ are for the example: $\mathrm{P}_{1}, \mathrm{P}_{2}, \mathrm{P}_{3}$, the parents of $\mathrm{P}_{4}\left(\mathrm{P}_{4 \mathrm{~S}}\right.$ and $\left.\mathrm{P}_{4 \mathrm{D}}\right)$, the parents of $P_{5}\left(P_{5 S}\right.$ and $\left.P_{5 D}\right), P_{6}$, and the parents of $P_{7}\left(P_{7 S}\right.$ and $\left.P_{7 D}\right)$.

To make $\mathrm{A}_{10} \mathrm{Q}_{0}=\mathrm{Q}, \mathrm{Q}_{0}$ would need to be:

$$
Q_{0}=\left(\begin{array}{llll}
1 & 0 & 0 & 0 \\
0 & 1 & 0 & 0 \\
1 & 0 & 0 & 0 \\
0 & 1 & 0 & 0 \\
0 & 1 & 0 & 0 \\
0 & 0 & 0 & 1 \\
0 & 0 & 0 & 1 \\
0 & 0 & 1 & 0 \\
0 & 0 & 1 & 0 \\
0 & 0 & 1 & 0
\end{array}\right)
$$


Note that both parents of $\mathrm{P}_{4}$ are assigned to group 2, both parents of $\mathrm{P}_{5}$ are assigned to group 4 , and both parents of $P_{7}$ are assigned to group 3. That strategy results in the direct and maternal group effects being assigned equivalently. The rules for calculating $W$ accommodate having both parents assigned to the same group. Care must be taken, however, in programming the calculation (Quaas, 1988). In calculation of sums of squares and products for regression or of coefficients for least squares equations, a programmer often will take advantage of the symmetry to calculate, say $\operatorname{Coef}(\mathrm{I}, \mathrm{J})$ and then write $\operatorname{Coef}(\mathrm{J}, \mathrm{I}) \leftarrow \operatorname{Coef}(\mathrm{I}, \mathrm{J})$.

In calculation of $\mathrm{W}$ when $\mathrm{I}=\mathrm{J}$, as with both proxy parents assigned to the same group, what may happen is the following:

$$
\begin{aligned}
& \mathrm{W}(\mathrm{I}, \mathrm{I}) \leftarrow \mathrm{W}(\mathrm{I}, \mathrm{I})+.25 \\
& \mathrm{~W}(\mathrm{I}, \mathrm{J}) \leftarrow \mathrm{W}(\mathrm{I}, \mathrm{J})+.25 \\
& \mathrm{~W}(\mathrm{~J}, \mathrm{I}) \leftarrow \mathrm{W}(\mathrm{I}, \mathrm{J}) \\
& \mathrm{W}(\mathrm{J}, \mathbf{J}) \leftarrow \mathrm{W}(\mathrm{J}, \mathrm{J})+.25
\end{aligned}
$$

In that case, .75 (i.e., $3 \times .25$ ) will be added rather than 1.00 (i.e., $4 \times .25$ ) to $W(I, I)$.

Another possibility is to switch the last two steps with the same result. Experience has shown that strange solutions come forth from such an error.

\section{Example}

Assume for simplicity that $\beta=\mu$ and $\mathrm{p}$ (nongenetic maternal effects) is null.

Assume that the records of $\mathrm{B}, \mathrm{C}_{1}, \mathrm{C}_{2}, \mathrm{C}_{3}$, and $\mathrm{C}_{4}$ are $100,110,120,130$, and 140 .

\begin{tabular}{|c|c|c|c|}
\hline Animal & Sire (or proxy) & Dam (or proxy) & $\mathrm{D}$ \\
\hline $\mathbf{P}_{4}$ & $\mathrm{~g}_{2}$ & $\mathrm{~g}_{2}$ & 1 \\
\hline $\mathbf{P}_{5}$ & $\mathrm{~g}_{4}$ & $\mathrm{~g}_{4}$ & 1 \\
\hline $\mathbf{P}_{7}$ & $\mathrm{~g}_{3}$ & $\mathrm{~g}_{3}$ & 1 \\
\hline $\mathrm{S}$ & $\mathrm{g}_{1}$ & $\mathrm{~g}_{2}$ & 1 \\
\hline B & $\mathrm{g}_{1}$ & $\mathrm{P}_{4}$ & $4 / 3$ \\
\hline $\mathrm{C}_{1}$ & $\mathrm{~S}$ & $\mathrm{P}_{5}$ & 2 \\
\hline $\mathrm{C}_{2}$ & $\mathrm{~S}$ & $\mathrm{~B}$ & 2 \\
\hline $\mathrm{C}_{3}$ & $g_{3}$ & B & $4 / 3$ \\
\hline $\mathrm{C}_{4}$ & $\mathrm{C}_{1}$ & $P_{7}$ & 2 \\
\hline
\end{tabular}

Assume $\sigma_{\mathrm{e}}^{2}=10$ and $\quad\left(\begin{array}{ll}\sigma_{\mathrm{a}}^{2} & \sigma_{\mathrm{am}} \\ \sigma_{\mathrm{am}} & \sigma_{\mathrm{m}}^{2}\end{array}\right)=\left(\begin{array}{rr}4.0 & .5 \\ .5 & 1.0\end{array}\right)$

so that $\alpha=2 . \overline{6}, \lambda=-1 . \overline{3}$, and $\gamma=10 . \overline{6}$. The. $\bar{F}$ notation is for a repeating decimal. The lists of animals, sires or proxy groups, dams or proxy groups, and corresponding $\mathrm{D}$ are:

Then $\mathrm{W}$ will correspond to animals, $\mathrm{P}_{4}, \ldots, \mathrm{C}_{4}$, and groups, $\mathrm{g}_{1}, \ldots, \mathrm{g}_{4}$.

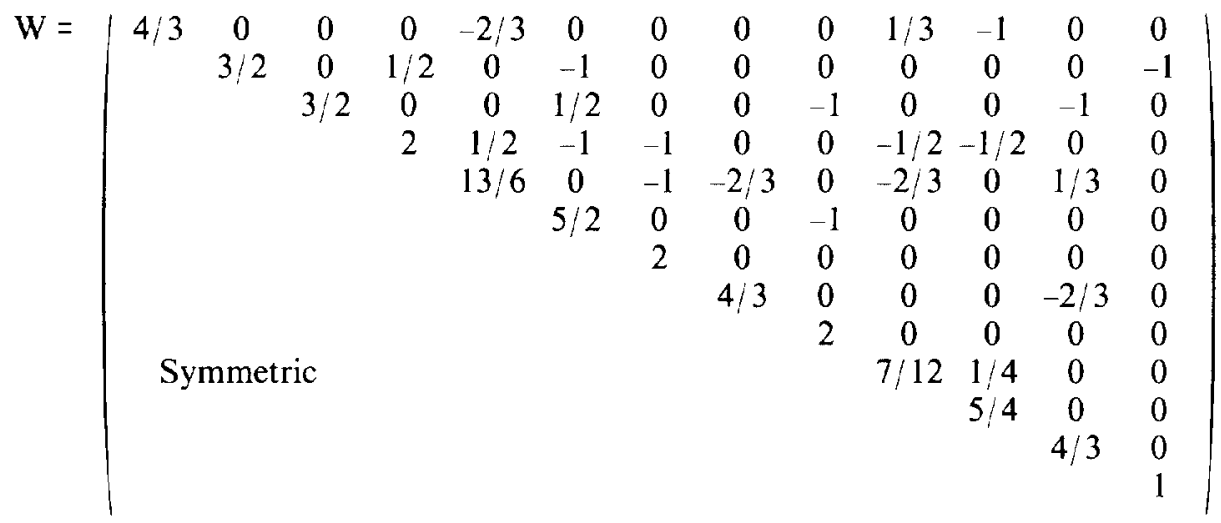


Note that the usual check that each row of W sums to zero is satisfied.

The equations will be written in the form:

$$
\left(\begin{array}{ccc}
\mathrm{X}^{\prime} \mathrm{X} & \mathrm{X}^{\prime} \mathrm{Z}_{+} & \mathrm{X}^{\prime} \mathrm{S}_{+} \\
\mathrm{Z}_{+}^{\prime} \mathrm{X} & \mathrm{Z}_{4}^{\prime} \mathrm{Z}_{+}+\alpha \mathrm{W} & \mathrm{Z}_{+}^{\prime} \mathrm{S}_{+}+\lambda \mathrm{W} \\
\mathrm{S}_{+}^{\prime} \mathrm{X} & \mathrm{S}_{+}^{\prime} \mathrm{Z}_{+}+\lambda \mathrm{W} & \mathrm{S}_{+}^{\prime} \mathrm{S}_{+}^{+} \gamma \mathrm{W}
\end{array}\right) \quad\left(\begin{array}{c}
\hat{\beta} \\
\hat{\mathrm{a}}_{*} \\
\hat{\mathrm{m}}_{*}
\end{array}\right)=\left(\begin{array}{c}
\mathrm{X}^{\prime} \mathrm{y} \\
\mathrm{Z}_{+}^{\prime} \mathrm{y} \\
\mathrm{S}_{+}^{\prime} \mathrm{y}
\end{array}\right)
$$

The coefficient matrix for the example is:

\begin{tabular}{|c|c|c|c|c|c|c|c|c|c|c|c|c|c|c|c|c|c|c|c|c|c|c|c|c|c|c|}
\hline \multirow{27}{*}{\multicolumn{2}{|c|}{5.0}} & 0 & 0 & 0 & 1.0 & 1.0 & 1.0 & 1.0 & 1.0 & 0 & 0 & 0 & 0 & 1.0 & 1.0 & 1.0 & 0 & 2.0 & 0 & 0 & 0 & 0 & 0 & 0 & 0 & 0 \\
\hline & & $\begin{array}{ll}3.50 \\
0\end{array}$ & 0 & 0 & -1.7 & 0 & 0 & 0 & 0 & .8 & .2 .6 & 0 & 0 & -1.7 & 0 & 0 & 0 & .8 & 0 & 0 & 0 & 0 & -.4 & 1.3 & 0 & 0 \\
\hline & & 4.0 & 0 & 1.3 & 0 & -2.6 & 0 & 0 & 0 & 0 & 0 & 0 & -2.6 & 0 & -2.0 & 0 & -.6 & 0 & 1.3 & 0 & 0 & 0 & 0 & 0 & 0 & 1.3 \\
\hline & & & 4.0 & 0 & 0 & 1.3 & 0 & 0 & -2.6 & 0 & 0 & -2.6 & 0 & 0 & 0 & -2.0 & 0 & 0 & -.6 & 0 & 0 & 1.3 & 0 & 0 & 1.3 & 0 \\
\hline & & & & 5.3 & 1.3 & -2.6 & -2.6 & 0 & 0 & $\ldots 1.3$ & -1.3 & 0 & 0 & 0 & -.6 & 0 & -2.6 & -.6 & 1.3 & 1.3 & 0 & 0 & .6 & .6 & 0 & 0 \\
\hline & & & & & 6.7 & 0 & -2.6 & -1.7 & 0 & -1.7 & 0 & .8 & 0 & 1.8 & 0 & 0 & -.6 & -2.8 & 0 & 1.3 & .8 & 0 & .8 & 0 & -.4 & 0 \\
\hline & & & & & & 7.6 & 0 & 0 & -2.6 & 0 & 0 & 0 & 0 & 0 & 2.3 & -.6 & 1.3 & 0 & -3.3 & 0 & 0 & 1,3 & 0 & 0 & 0 & 0 \\
\hline & & & & & & & 6.3 & 0 & 0 & 0 & 0 & 0 & 0 & 0 & 0 & 0 & 1.3 & 2.3 & 0 & -2.6 & 0 & 0 & 0 & 0 & 0 & 0 \\
\hline & & & & & & & & 4.5 & 0 & 0 & 0 & -1.7 & 0 & 0 & 0 & 0 & 0 & 1.8 & 0 & 0 & -1.7 & 0 & 0 & 0 & .8 & 0 \\
\hline & & & & & & & & & 6.3 & 0 & 0 & 0 & 0 & 0 & 0 & 2.3 & 0 & 0 & 1.3 & 0 & 0 & -2.6 & 0 & 0 & 0 & 0 \\
\hline & & & & & & & & & & 1.5 & .6 & 0 & 0 & -.4 & 0 & 0 & .6 & .8 & 0 & 0 & 0 & 0 & -.7 & -.3 & 0 & 0 \\
\hline & & & & & & & & & & & 3.3 & 0 & 0 & 1.3 & 0 & 0 & .6 & 0 & 0 & 0 & 0 & 0 & -.3 & -1.6 & 0 & 0 \\
\hline & & & & & & & & & & & & 3.5 & 0 & 0 & 0 & 1.3 & 0 & -.4 & 0 & 0 & .8 & 0 & 0 & 0 & -1.7 & 0 \\
\hline & & & & & & & & & & & & & 2.6 & 0 & 1.3 & 0 & 0 & 0 & 0 & 0 & 0 & 0 & 0 & 0 & 0 & -1.3 \\
\hline & & & & & & & & & & & & & & 15.2 & 0 & 0 & 0 & -7.1 & 0 & 0 & 0 & 0 & 3.5 & -10.6 & 0 & 0 \\
\hline & & & & & & & & & & & & & & & 17.0 & 0 & 5.3 & 0 & -10.6 & 0 & 0 & 0 & 0 & 0 & 0 & $-10,6$ \\
\hline & & all de & $\operatorname{cim}$ & als & are & rep & eati & ng & & & & & & & & 17.0 & 0 & 0 & 5.3 & 0 & 0 & -10.6 & 0 & 0 & -10.6 & 0 \\
\hline & & i.e., & 3.5 & is $r$ & eall & y 3. & 555 & & & & & & & & & & 21.3 & 5.3 & -10.6 & 10.6 & 0 & 0 & -5.3 & -5.3 & 0 & 0 \\
\hline & & & cien & $\mathrm{t} \mathrm{m}$ & atri & $x$ & si & $\mathrm{mI}$ & etri & & & & & & & & & 25.1 & 0 & 10.6 & -7.1 & 0 & -7.1 & 0 & 3.5 & 0 \\
\hline & & & & & & & & & & & & & & & & & & & 26.6 & 0 & 0 & -10.6 & 0 & 0 & 0 & 0 \\
\hline & & & & & & & & & & & & & & & & & & & & 21.3 & 0 & 0 & 0 & 0 & 0 & 0 \\
\hline & & & & & & & & & & & & & & & & & & & & & 14.2 & 0 & 0 & 0 & -7.1 & 0 \\
\hline & & & & & & & & & & & & & & & & & & & & & & 21.3 & 0 & 0 & 0 & 0 \\
\hline & & & & & & & & & & & & & & & & & & & & & & & 6.2 & 2.6 & 0 & 0 \\
\hline & & & & & & & & & & & & & & & & & & & & & & & & 13.3 & 0 & 0 \\
\hline & & & & & & & & & & & & & & & & & & & & & & & & & 14.2 & 0 \\
\hline & & & & & & & & & & & & & & & & & & & & & & & & & & 10.6 \\
\hline
\end{tabular}

The right-hand side vector is:

$\left(\begin{array}{cccccccccccccc}600 & 0 & 0 & 0 & 0 & 100 & 110 & 120 & 130 & 140 & 0 & 0 & 0 & 0 \\ & 100 & 110 & 140 & 0 & 250 & 0 & 0 & 0 & 0 & 0 & 0 & 0 & 0\end{array}\right)^{\prime}$.

The solution vector obtained using a generalized (Penrose) inverse of the coefficient matrix (PINV of MATLAB; Moler, 1981) is:

$\begin{array}{rrrrrrrrrrrrrr}160.8 & 2.3 & 4.7 & 23.4 & 3.4 & 3.4 & 4.0 & 3.4 & 13.4 & 13.7 & 4.6 & 2.3 & 23.4 & 4.7 \\ & -10.2 & -.9 & 19.5 & 9.8 & 9.8 & 4.5 & 9.8 & 14.6 & 12.0 & 29.8 & -10.2 & 19.5 & -.9)^{\prime}\end{array}$.

These solutions probably do not make much sense but do illustrate that the interdependencies among the rows (and columns) of the coefficient matrix are complex. The solutions will depend on the constraints assigned or the approach used to obtain a generalized inverse.

The expectations of the solutions, which in themselves do not look unusual, illustrate the complexity. The expectations were obtained by premultiplying the expectations of the right-hand sides by the generalized inverse of the coefficient matrix.

The expectations of solutions for the effects as shown in Table 1 exhibit the complexity. Such a result for an example with five observations used to estimate nine fixed effects and to predict nine direct and nine maternal breeding values should be expected. Nevertheless, the breeding 
BREEDING VALUES WTTH MATERNAL GROUPS

TABLE 1. COEFFICIENTS FOR FIXED EFFECTS IN THE EXPECTATIONS OF SOLUTIONS FOR FINAL EFFECTS IN THE EXAMPLE

\begin{tabular}{|c|c|c|c|c|c|c|c|c|c|}
\hline Solution & $\mu$ & $g_{a}$ & $\mathrm{~g}_{\mathrm{a} 2}$ & $\mathrm{~g}_{\mathrm{a} 3}$ & $g_{a 4}$ & $\mathrm{~g}_{\mathrm{ml}}$ & $\mathrm{g}_{\mathrm{m} 2}$ & $\mathrm{~g}_{\mathrm{m} 3}$ & $\mathrm{~g}_{\mathrm{m} 4}$ \\
\hline$\hat{\mu}$ & .864 & .249 & .249 & .216 & .150 & .199 & .262 & .204 & .199 \\
\hline$\hat{\mathrm{g}}_{\mathrm{a} 1}$ & .097 & .250 & .250 & -.363 & -.040 & .075 & .104 & -.004 & -.078 \\
\hline$\hat{\mathrm{g}}_{\mathrm{a} z}$ & .049 & .125 & .125 & -.181 & -.020 & .037 & .052 & -.002 & -.039 \\
\hline$\hat{\mathrm{g}}_{\mathrm{a} 3}$ & .073 & .312 & -.312 & .728 & .030 & .056 & .078 & -.003 & -.058 \\
\hline$\hat{\mathrm{g}}_{\mathrm{a} 4}$ & .051 & -.040 & -.040 & .031 & .162 & -.130 & $\ldots .186$ & .084 & .283 \\
\hline$\hat{\mathrm{g}}_{\mathrm{m} !}$ & .063 & .064 & .064 & .056 & -.120 & .745 & .340 & -.200 & -.140 \\
\hline$\hat{\mathrm{g}}_{\mathrm{m} 2}$ & .063 & .064 & .064 & .056 & -.120 & -.255 & .660 & -.200 & -.140 \\
\hline$\hat{\mathrm{g}}_{\mathrm{m} 3}$ & .068 & -.004 & -.004 & -.004 & .082 & -.209 & -.274 & .777 & -.226 \\
\hline$\hat{\mathrm{g}}_{\mathrm{m} 4}$ & .074 & .072 & -.072 & -.065 & .283 & -.162 & -.208 & -.244 & .689 \\
\hline
\end{tabular}

value solutions are dependent on the generalized inverse that is used or is implied by iteration of unconstrained equations. Quaas (1988), Henderson (1988), and earlier personal communications from R. L. Quaas, C. R. Henderson and I. Misztal have cautioned that the group equations are not independent.

If the constraint, $\hat{\mu}=\mathbf{0}$, is imposed or the restriction, $\mu=0$, is included in the model, the solutions and expectations are different from the solutions from the generalized inverse of the unconstrained or unrestricted equations. For either $\hat{\mu}=0$ or $\mu=0$, the solutions are the same and the expectations are the same except that with $\hat{\mu}=0$ the expectations contain $\mu$, whereas with $\mu=0$ the expectations cannot contain $\mu$.

A better example may be to limit the model to direct effects and restrict $\mu$ to be zero for the same data, i.e., five records and four group effects. The MME are:

$$
\left(\mathrm{Z}_{+}^{\prime} \mathrm{Z}_{+}+\alpha \mathrm{W}\right)\left(\hat{\mathrm{a}}_{*}\right)=\mathrm{Z}_{+}^{\prime} \mathrm{y}
$$

With $\alpha=10 / 4=2.5$ the coefficient matrix is:

$\left.\begin{array}{|ccccccccccccc}3.33 & 0 & 0 & 0 & -1.67 & 0 & 0 & 0 & 0 & .83 & -2.50 & 0 & 0 \\ & 3.75 & 0 & 1.25 & 0 & -2.50 & 0 & 0 & 0 & 0 & 0 & 0 & -2.50 \\ & 3.75 & 0 & 0 & 1.25 & 0 & 0 & -2.50 & 0 & 0 & -2.50 & 0 \\ & & 5.00 & 1.25 & -2.50 & -2.50 & 0 & 0 & -1.25 & -1.25 & 0 & 0 \\ & & & 6.42 & 0 & -2.50 & -1.67 & 0 & -1.67 & 0 & .83 & 0 \\ & & & & 7.25 & 0 & 0 & -2.50 & 0 & 0 & 0 & 0 \\ & & & & & 6.00 & 0 & 0 & 0 & 0 & 0 & 0 \\ \text { Symmetric } & & & & & & 4.33 & 0 & 0 & 0 & -1.67 & 0 \\ & & & & & & & & & 1.46 & .62 & 0 & 0 \\ & & & & & & & & & 3.12 & 0 & 0 \\ & & & & & & & & & & 3.33 & 0 \\ & & & & & & & & & & & & 2.50\end{array}\right)$.

The right-hand side vector is:

$$
\left(\begin{array}{lllllllllllll}
0 & 0 & 0 & 0 & 100 & 110 & 120 & 130 & 140 & 0 & 0 & 0 & 0
\end{array}\right)^{\prime} .
$$

The solution vector is:

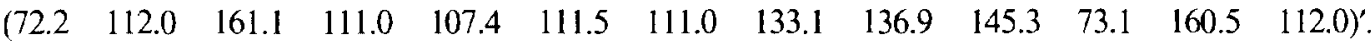

The expectations shown in Table 2 correspond to the models for breeding values except that groups 1 and 2 are confounded. Note that $E\left[\hat{g}_{a 1}+\hat{g}_{a 2}\right]=g_{a 1}+g_{a 2}$ even though $E\left[\hat{g}_{a 1}\right]=.67\left(g_{a 1}+g_{a 2}\right)$ and $\mathrm{E}\left[\hat{\mathrm{g}}_{\mathrm{a} 2}\right]$ ㅁ.33( $\left.\mathrm{g}_{\mathrm{a} 1}+\mathrm{g}_{\mathrm{a} 2}\right)$; i.e., $\mathrm{g}_{\mathrm{a} 1}+\mathrm{g}_{\mathrm{a} 2}$ is estimable. This example was examined in detail. 
TABLE 2. EXPECTATIONS FOR SOLUTIONS TO THE EXAMPLE OF ONLY ADDITIVE DIRECT EFFECTS

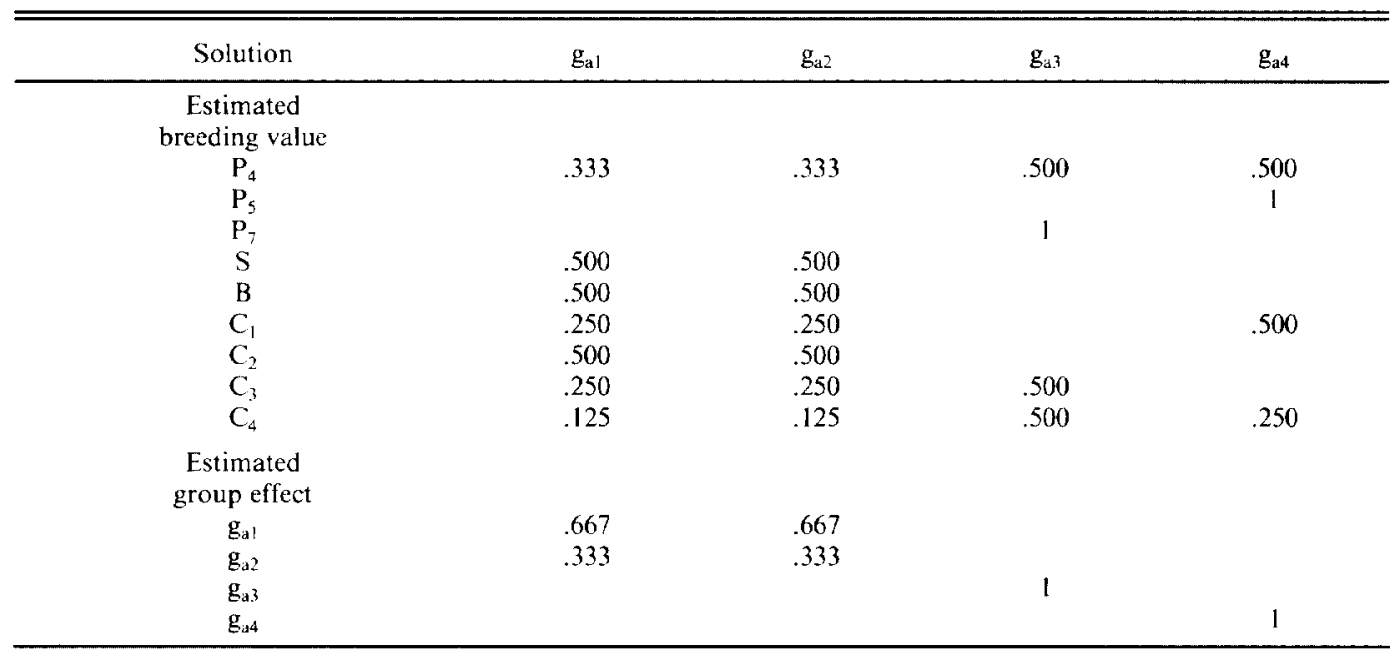

For various equivalent sets of mixed-model equations for direct effects only with no $\beta$ vector, the same result always occurred for this example, although the proportionality of $E\left[\hat{\mathrm{g}}_{\mathrm{al}}\right]$ and $E\left[\hat{\mathbf{g}}_{\mathrm{a} 2}\right]$ varied. Equations were set up considering all relationships and the group effects in the usual way for mixed models but with from 6 to 27 animals included in the augmented equations. In those cases, solutions were always the same with the unexpected result that $E\left[\hat{g}_{a 1}\right]=.5\left(g_{a 1}+g_{a 2}\right)$ and $E\left[\hat{g}_{a 2}\right] \square .5\left(g_{a 1}+g_{a 2}\right)$, evidently because of the generalized inverse that was generated for the coefficient matrix.

This example with a small number of observations does not mean that such problems will exist with larger data sets. The example does serve to emphasize the warnings of Henderson, Misztal and Quaas.

\section{Implications}

The procedure described here allows breeding values for models with additive direct and additive maternal genetic effects to be computed using the same efficient algorithm as can be used for computing breeding values only for additive direct genetic effects. Breeding values (deviations plus appropriate group effects) are computed for all animals for both direct and maternal effects. Groups are assigned the same way for direct and for maternal effects. Parents of dams without records are both assigned to the group the dam, as a most recent ancestor without a record, would have been assigned for models that ignore maternal effects. Animal models now in use for beef cattle evaluation do not include genetic group effects for direct and maternal effects (Benyshek et al., 1988; Robinson and Chesnais, 1988). Those programs can be modified easily to include group effects. A subsequent paper will develop rules for setting up equations for a reduced animal model (Quaas and Pollak, 1980) based on the ideas and model described here.

\section{Literature Cited}

Benyshek, L. L., M. H. Johnson, D. E. Little, J. K. Bertrand and L. A. Kriese. 1988. Application of an animal model in the United States beef cattle industry. Proc. Animal Workshop. J. Dairy Sci. 71(Suppl.2):35.

Henderson, C. R. 1976. A simple method for computing the inverse of a numerator relationship matrix used in prediction of breeding values. Biometrics 32:69.
Henderson, C. R. 1977. Best linear unbiased prediction of breeding values not in the model for records. J. Dairy Sci. 60:783.

Henderson, C. R. 1985. Equivalent linear models to reduce computations. J. Dairy Sci. 68:2267.

Henderson, C. R. 1988. Theoretical basis and computational methods for a number of different animal models. Proc. Animal Model Workshop. J. Dairy Sci. 71(Suppl.2): 1 .

Moler, C. 1981. MATLAB User's Guide. Department of 
Computer Science, Univ. of New Mexico, Las Cruces (mimeo).

Quaas, R. L. 1976. Computing the diagonal elements and inverse of a large numerator relationship matrix. Biometrics 32:949

Quaas, R. L. 1988. Additive genetic model with groups and relationships. J. Dairy Sci. 71:1338.

Quaas, R. L. and E. J. Pollak. 1980. Mixed model methodology for farm and ranch beef cattle testing programs. J. Anim. Sci. 51:1277.

Quaas, R. L. and E. J. Pollak. 1981. Modified equations for sire models with groups. J. Dairy Sci. 64:1868.

Quaas, R. L. and E. J. Pollak. 1987. RAM problems of base, grouping and accuracy. In: Proc. Workshop II: Prediction of Genetic Value for Beef Cattle, pp 53-71. Beef Imp. Fed. and Winrock Int., Kansas City, MO.

Robinson, G. K. 1986. Group effects and computing strategies for models for estimating breeding values. J. Dairy Sci, 69:3106.

Robinson, J.A.B., and J. P. Chesnais. 1988. Application of the animal model on a national basis to the evaluation of Canadian livestock. Proc. Animal Model
Workshop. J. Dairy Sci. 71(Suppl.2):70.

Schaeffer, L. R. and B. W. Kennedy. 1986a, Computing strategies for solving mixed model equations. J. Dairy Sci. 69:575.

Schaeffer, L. R. and B. W. Kennedy. 1986b. Computing solutions to mixed model equations. In: Proc. 3rd World Congr. Genet. Appl. Livest. Prod., p 392. Lincoln, NE

Thompson, R. 1979. Sire evaluation. Biometrics 35:339.

Westell, R. A. 1984. Simultaneous evaluations of sires and cows for a large population. Ph.D. thesis, Cornell Univ, Ithaca, NY.

Westell, R. A., R. L. Quaas and L. D. Van Vleck. 1984. Genetic groups in an animal model. J. Anim. Sci 59(Suppl.1):175. (Abstr.).

Westell, R. A., R. L. Quaas and L. D. Van Vleck. 1988 Genetic groups in an animal model. J. Dairy Sci. $71: 1310$.

Wiggans, G. R., I. Misztal and L. D. Van Vleck. 1988 Animal model evaluation of Ayrshire milk vield with all lactations, herd-sire interaction, and groups based on unknown parents. J. Dairy Sci. 71:1319. 